\title{
HUBUNGAN FAKTOR OSEANOGRAFI DENGAN HASIL TANGKAPAN PELAGIS BESAR DI PERAIRAN BATANG DUA PROPINSI MALUKU UTARA
}

\author{
Sadam Sahidi*, Gusti D. Sapsuha*, Ahmad F. Laitupa*, Umar Tangke** \\ *Alumni THP FAPERTA UMMU-Ternate, Email: : \\ **Staf Pengajar Prodi THP FAPERTA UMMU-Ternate, Email: khakafart@yahoo.com
}

\begin{abstract}
ABSTRAK
Penggunaan armada penangkapan ikan di yang sebagian besar menggunakan cara konvensional, sehingga waktu operasi penangkapan ikan lebih banyak dipakai untuk mencari daerah penangkapan ikan. Cara ini tentunya kurang efektif dan efisien, maka perlu dilakukan penelitian untuk mengkaji hubungan antara hasil tangkapan ikan pelagis besar diantaranya ikan cakalang, madidihang dan tongkol dengan faktor oseanografi untuk dapat mengetahui distribusinya di perairan pesisir pulau Batang Dua sehingga dalam melakukan operasi penangkapan nelayan tidak lagi menggunakan pengalaman, tetapi memanfaatkan informasi tersebut. Penelitian dengan tujuan untuk mengkaji hubungan antara hasil tangkapan ikan pelagis dengan faktor oseanografi di pesisir pulau Batang Dua Prop. Maluku Utara dilaksanakan selama bulan maret sampai mei 2015 dengan menggunakan metode survey dan analisis regresi untuk melihat hubungan hasil tangkapan dengan parameter oseanografi. Hasil penelitian terlihat bahwa secara bersama-sama parameter oseanografi berpengaruh terhadap hasil tangkapan dengan $\left(F_{\text {Hit }} 14.544>F_{\text {Tabel }} 3.172\right)$ dan $R^{2}=$ 0.618, uji $t$ menunjukan bahwa secara individu hasil tangkapan hanya dipengaruhi oleh dua factor oseanografi yakni SPL dan Klorofil-a dengan nilai koefisien determinasi $\left(R^{2}\right) 0.4228$ untuk SPL dan 0.5313 untuk klorofil-a dan sebaran SPL dan klorofil-a pada daerah penangkapan selama penelitian (MaretMei 2015) masing-masing adalah 28.3-30.8 ${ }^{\circ} \mathrm{C}$ untuk SPL dan 0.03-0.35 untuk klorofil-a dengan total jumlah hasil tangkapan $1.669 .93 \mathrm{~kg}$.
\end{abstract}

Kata Kunci: Cakalang, Madidhang, Tongkol, Batang Dua

\section{PENDAHULUAN}

1.1. Latar Belakang

Eksploitasi sumberdaya perikanan sampai pada tingkat lestari sangat erat kaitannya dengan sistem operasi usaha penangkapan ikan. penggunaan armada penangkapan ikan di yang sebagian besar menggunakan cara konvensional, sehingga waktu operasi penangkapan ikan lebih banyak dipakai untuk mencari daerah penangkapan ikan. Cara ini tentunya kurang efektif dan efisien, karena membutuhkan biaya operasional cukup mahal dan hasil tangkapan yang kurang maksimal.Untuk menunjang peningkatan produksi hasil tangkapan, maka perlu dilakukan penelitian tentang distribusi sehingga dalam melakukan operasi penangkapan nelayan tidak lagi menggunakan pengalaman, tetapi memanfaatkan informasi distribusi ikan tersebut. Sehubungan dengan hal tersebut makaalternatif yang berhubungan dengan usaha untuk penentuan atau prakiraan lokasi ikan akan sangat membantu untuk meningkatkan efektifitas dan efisiensi operasi penangkapan. Fluktuasi parameter biofisik atau oseanografi adalah faktor utama yang mungkin harus dikaji dalam hubungannya dengan distribusi ikan tersebut.

Parameter oseanografi yang berkaitan erat dengan distribusi ikan antara lain 
kelimpahan plankton, suhu, arus, salinitas dan liannya. Pemanfaatan faktor ini sangat bermanfaat untuk pemanfaatan dan pengelolaan sumberdaya ikan, terutama dalam usaha penangkapan.Pemantauan penting karena berbagai perubahan di perairan laut dapat menyebabkan perubahan adaptasi dan tingkah laku ikan, dimana setiap jenis ikan memiliki kisaran toleransi suhu tertentu untuk kelangsungan hidupnya. Oleh sebab itu maka adanya sebaran plankton, suhu dan perubahannya serta pola arus yang terjadi akan mempengaruhi ikan dalam beraktivitas terutama dalam mencari makan, bertelur, melakukan ruaya dan migrasi.

Laut Maluku Utara merupakan wilayah perairan yang memiliki potensi perikanan cukup besar, posisinya sebagai penghubung antara samudra Pasifik dan samudra Hindia menyebabkan sifat massa airnya merupakan kombinasi dari kedua perairan tersebut. Massa air dari masing-masing perairan memiliki karakteristik oseanografi yang berbeda sehingga percampuran massa air dapat merupakan wilayah potensial untuk penangkapan ikan jenis tertentu misalnya jenis ikan pelagis. Selain itu daerah tersebut juga merupakan wilayah migrasi berbagai jenis ikan pelagis diantaranya ikan cakalang (Katsuwonus pelamis) dan madidihang (Thunnus albacares).

Ikan cakalang (Katsuwonus pelamis) dan ikan madidihang (Thunnus albacares) merupakan sumberdaya ikan yang potensial dikembangkan khususnya di wilayah Laut Provinsi Maluku Utara. Jenis ikan tersebut merupakan salah satu sumber pendapatan penting nelayan. Ikan cakalang dan madidihangmerupakan sumber protein hewanidengan kandungan omega-3 yang sangat diperlukan oleh tubuh. Sebagai sumberdayayangbernilai ekonomis tinggi dan mempunyai pangsa pasar yang luas, pengusahaan cakalang dan madidihang turut berperan dalam perkembangan ekonomi Indonesia. Oleh karena itu, cukup beralasan jika pemanfaatan sumberdaya ikan cakalang dan ikan madidihang ini terus meningkat. potensiikan cakalang dan madidihang di perairan Indonesia adalah 780.040 ton/tahun. Sumberdaya ikan cakalang dan ikan madidihang cukup menyebar di perairan
Indonesia, dari barat hingga ke timur, dan lebih banyak menyebar di perairan lepas pantai. Pemanfaatan sumberdaya ikan cakalang dan madidihang lebih banyak dilakukan oleh perusahaan skala menengah ke atas, karena memerlukan investasi yang relatif besar.Masalah utama yang dihadapi nelayan dalam menangkap ikan cakalang dan ikan madidihang cakalang adalah ketidakpastian daerah distribusi dan kelimpahan ikan perenang cepat tersebut. Penentuan daerah penangkapan tuna dan cakalang dengan tepat dan akurat dapat dilakukan dengan mengkombinasikan data survei lapangan dan data satelit.

Ketersediaan data merupakan salah satu kendala utama dalam menentukan distribusi ikan di perairan. Disadari bahwa sampai saat ini masih terdapat kesenjangan data oseanografi khususnya untuk perairan lepas pantai, hal ini disebabkan oleh sulitnya kegiatan survei berbagai parameter osenografi secara langsung, selain itu sifat perairan yang dinamis sehingga memerlukan frekuensi pengamatan yang tinggi untuk cakupan daerah yang luas. Untuk memenuhi keperluan ini, maka dibutuhkan suatu penelitian untuk mengetahui hubungan antaran faktor oseanografi dengan hasil tangkapan ikan untuk memperoleh suatu informasi distribusi ikan cakalang dan madidihang di perairan laut Maluku.

\subsection{Tujuan dan Manfaat Penelitian}

Penelitian ini bertujuan untuk mengkaji hubungan antara hasil tangkapan ikan pelagis besar yakni ikan cakalang, madidihang dan tongkol dengan faktor oseanografi sehingga dapat mengetahui distribusinya di perairan laut Maluku. Manfaat penelitian ini adalah sebagai data base dan sebagai bahan informasi untuk peningkatan efisiensi dan efektifitas operasi penangkapan oleh nelayan untuk menghemat waktu, biaya termasuk BBM dan tenaga yang digunakan untuk mencari lokasi penangkapan ikan cakalang dan ikan madidihang.

\section{METODE PENELITIAN}

\subsection{Waktu dan Tempat}

Penelitian ini direncanakan dilaksanakan pada bulan Maret - Mei 2015, bertempat di 
perairan Batang dua, Maluku Utara Provinsi dengan fishing base untuk melakukan kegiatan penangkapan berada di Kota Ternate.

\subsection{Alat dan Bahan}

Peralatan penelitian yang digunakan dapat dilihat pada Tabel 1, sedangkan bahan yang digunakan dalam penelitian ini adalah : Tabel 1. Alat-Alat Yang Digunakan Dalam Penelitian

\begin{tabular}{ll}
\hline Nama Alat & Kegunaan \\
\hline $\begin{array}{l}\text { Alat Tangkap Pole } \\
\text { and Line }\end{array}$ & Menangkap ikan \\
$\begin{array}{l}\text { Global Position } \\
\text { System }\end{array}$ & Menentukan posisi sampling \\
Kompas & Penentuan arah pelayaran \\
Thermometer & Mengukur suhu \\
Salinometer & Mengukur Salinitas \\
Kamera digital & Dokumentasi kegiatan \\
Alat tulis menulis & Mencatat data \\
Komputer & Mengolah data \\
\hline
\end{tabular}

\subsection{Jenis Penelitian}

Penelitian difokuskan untuk mencari parameter oseanografi yang berperan penting dalam mempengaruhi distribusi ikan cakalang dan ikan madidihang. Penelitian ini dilakukan dengan metode experimental fishing (pengambilan data penangkapan dan data oseanografi melalui sampling) digunakan untuk mengumpulkan data primer. Data primer terdiri dari data posisi penangkapan,data oseanografi (in-situ), dan data hasil tangkapan per trip.

\subsection{Analisis Data}

Data hasil penelitian diolah dengan menggunakan bantuan Software SPSS (Statistical Product and Service Solution) 17. Oleh karena pengambilan data umumnya di lakukan dilapangan dengan berbagai faktor yang sulit dikontrol yang dapat menyebabkan terjadinya bias pada data pengukuran, maka untuk analisis data di gunakan tingkat kepercayaan $90 \%$, yang artinya tingkat kesalahan yang diperbolehkan adalah sebasar $10 \%$. Data kondisi oseanografi dan data hasil tangkapan dianalisis menggunakan metode statistik sebagai berikut :

a) Analisis Regresi Berganda

Analisis regresi dipakai untuk menduga variabel tak bebas $(\mathrm{Y})$ atas variabel bebas $(\mathrm{X})$,
Analisis ini biasa digunakan untuk satu, dua atau beberapa variabel bebas dan satu variabel terikat. Karena variabel bebas lebih dari satu, maka persamaan matematik yang dibuat yaitu persamaan regresi berganda. Walpole (1992), menulis persamaannya secara umum yaitu:

$$
\widehat{y}=a+b_{1} x_{1}+b_{2} x_{2}+b_{3} x_{3}+\ldots b_{n} x_{n}
$$

Jika persamaan matematika tersebut di pakai untuk analisis data hasil tangkapan yellowfin tuna sebagai nilai variabel bebas $(y)$ dengan Variabel tak bebas suhu $\left(x_{1}\right)$, klorofil-a $\left(x_{2}\right)$, salinitas $\left(x_{3}\right)$, maka persamaan akan menjadi :

$$
\widehat{y}=a+b_{1} x_{1}+b_{2} x_{2}+b_{3} x_{3}+e
$$

Dimana :

$$
\begin{aligned}
& \hat{\boldsymbol{y}}=\text { Total hasil tangkapan } \\
& \text { yellowfin tuna } \\
& a=\text { Koefisien potongan } \\
& \text { (Konstanta) } \\
& b_{1}=\text { Koefisien regresi parameter } \\
& \text { suhu } \\
& b_{2}=\text { Koefisien regresi klorofil-a } \\
& b_{3}=\text { Koefisien regresi salinitas } \\
& x_{1}=\text { Suhu } \\
& x_{2}=\text { Klorofil-a }\left(\mathrm{mgm}^{-3}\right) \\
& x_{3}=\text { Salinitas }(\% \text { oo } \\
& e=\text { Standar Error }
\end{aligned}
$$

\section{b) Uji Normalitas}

Uji Normalitas dilakukan untuk mengetahui apakah suatu variabel normal atau tidak, normal dalam arti mempunyai distrbusi data yang normal. Ada dua cara untuk melihat kenormalan data yaitu secara visual dan dengan uji statistik. Secara visual menggunakan grafik dan histogram dengan asumsi yang digunakan berdasarkan grafik normal probability yang terbentuk, jika titik menyebar disekitar garis normal, maka data tersebut dapat dikatakan telah berdistribusi normal, begitu pula sebaliknya (Santosa, et al, 2005). Uji normalitas data dengan uji statistik digunakan Lilliefors Test (Kolmogorov-Smimov Test). Hipotesis yang digunakan yaitu $\mathrm{H}_{0}$ : data berdistribusi normal, $\mathrm{H}_{1}$ : data tidak berdistribusi normal. Jika nilai signifikan lebih besar 0,1 maka hipotesis tentang data berdistribusi normal akan diterima (gagal tolak $\mathrm{H}_{0}$ ), dan jika lebih kecil 0,1 maka data tidak berdistribsi normal (terima $\mathrm{H}_{1}$ ). Uji Kolmogorov Smirnov 
merupakan pengujian normalitas yang banyak dipakai, terutama setelah adanya banyak program statistik yang beredar. Kelebihan dari uji ini adalah sederhana dan tidak menimbulkan perbedaan persepsi di antara satu pengamat dengan pengamat yang lain, yang sering terjadi pada uji normalitas dengan menggunakan grafik.

\section{c) Analisis Varians (Uji F)}

Pengujian ini dilakukan untuk menguji pengaruh variabel bebas (independent)secara bersama terhadap variabel tak bebas (dependent). Dengan menggunakan program SPSS, maka hasil uji F dapat dilihat pada tabel Anova dimana jika nilai significance $F$ lebih kecil dari 0,1 berarti nyata dan jika lebih besar dan 0,1 berarti tidak nyata (Sudjana, 1996).

d) Analisis Koefisien Regresi (Uji $t)$

Uji $t$ dilakukan untuk melihat pengaruh masing-masing variabel bebas (independent) terhadap variabel tak bebas (dependent)sehingga diperoleh model regresi terbaik, Hasil dari uji $\mathbf{t}$ dengan menggunakan analisis SPSS dapat dilihat pada tabel summary output, jika nilai significance $\mathrm{t}$ lebih kecil dari taraf hipotesis 0,1 berarti nyata, dan jika lebih besar dari 0,1 berarti tidak nyata (Sudjana, 1996).

\section{HASIL DAN PEMBAHASAN}

3.1. Waktu Operasi Penangkapan Dan Hasil Tangkapan

Lama waktu operasi panangkapan atau trip adalah 2-b4 hari/trip, jumlah trip dalam sebulan adalah $7 \quad-12$ trip. Operasi penangkapan dilakukan dengan berangkat dari fishing base sekitar jam 15.00 - 17.00 WIT dan kembali ke fishing base rata-rata pada jam 19.00 - 20.00 WIT.

Hasil tangkapan selama penelitian (Gambar 1) dapat dilihat bahwa jumlah hasil tangkapan terendah selama operasi penangkapan adalah $879 \mathrm{~kg}$, sedangkan hasil tangkapan tertinggi sebesar $3.245 \mathrm{~kg}$. Rata-rata produksi/ hasil tangkapan selama kegiatan penelitian berjalan adalah sebesar 1.669 .93 $\mathrm{kg} /$ trip.

Jenis hasil tangkapan dengan alat tangkap pole and line selama penelitian yaitu ikan cakalang (Katsuwonus Pelamis),
Madidihang (Thunus Albacares) dan Tongkol (Euthynnus Afinnis).

$\Rightarrow$ Ikan cakalang adalah ikan pelagis besar yang termasuk dalam family Scombridea, genus Katsuwonus pelamis (Ikan cakalang) yang di tangkap selama operasi penangkapan pada waktu penelitian adalah ikan dengan ukuran panjang 30-45 cm, dengan berat rata-rata $5 \mathrm{~kg}$, tertangkap pada daerah 2 - 4 mil laut dari darat.

$\Rightarrow$ Ikan madidihang merupakan jenis ikan pelagis besar masih dalam family Scombridea, Genus Thunus dengan ciri-ciri badan memanjang, bulat, seperti cerutu. Memiliki dua cuping/lidah di antara kedua sirip perutnya. Ikan madidihang yang tertangkap selama operasi penangkapan pada waktu penelitian adalah ikan dengan ukuran panjang 30-40 cm, dengan berat $4 \mathrm{~kg}$, tertangkap pada daerah 2-4 mil laut dari daratan.

$\Rightarrow$ Ikan tongkol juga termasuk family scombridae, genus Euthynus, badan memanjang, seperti cerutu atau torpedo. Tergolong tuna kecil. Ikan tongkol yang tertangkap selama operasi penangkapan pada waktu penelitian adalah ikan dengan ukuran panjang $25 \mathrm{~cm}$, dengan berat ratarata $3 \mathrm{~kg}$, tertangkap pada daerah $2-4 \mathrm{mil}$ laut dari daratan.

\subsection{Penanganan Hasil Tangkapan}

Penanganan dengan pendinginan sangat beragam tergantung pada tempatnya (kapal penangkap, tempat pendaratan ikan, tempat pelelangan, pasar ikan, pabrik pengolahan ikan, supermarket, dan lain-lain), jenis ikan, dan tujuan pendinginan.Tetapi secara umum dapat di gariskan bahwa es harus di campurkan dengan ikan sedemikian rupa hingga setiap permukaan ikan bersinggungan dengan es, pendinginan berlansung jika es bersinggungan dengan ikan. Makin banyak permukaan ikan yang bersinggungan dengan es, maka pendinginan akan berlansung lebih cepat sehingga pembusukan dapat segera di hambat. Pekerjaan-pekerjaan yang di perlukan, sedapat mungkin di lakukan pada tempat yang dingin, atau sekurang-kurangnya di tempat teduh agar sinar matahari tidak dapat memanaskan ikan secara lansung. Faktor yang 
tidak kalah pentingnya dalam prosedur pendinginan ikan adalah kecepatan.Semua pekerjaan harus di lakukan dengan cepat agar suhu ikan dapat segera di turunkan.
Proses penanganan ikan pada saat kegiatan penelitian di kapal KM. Inka Mina 523 adalah seperti terlihat pada Gambar 2.

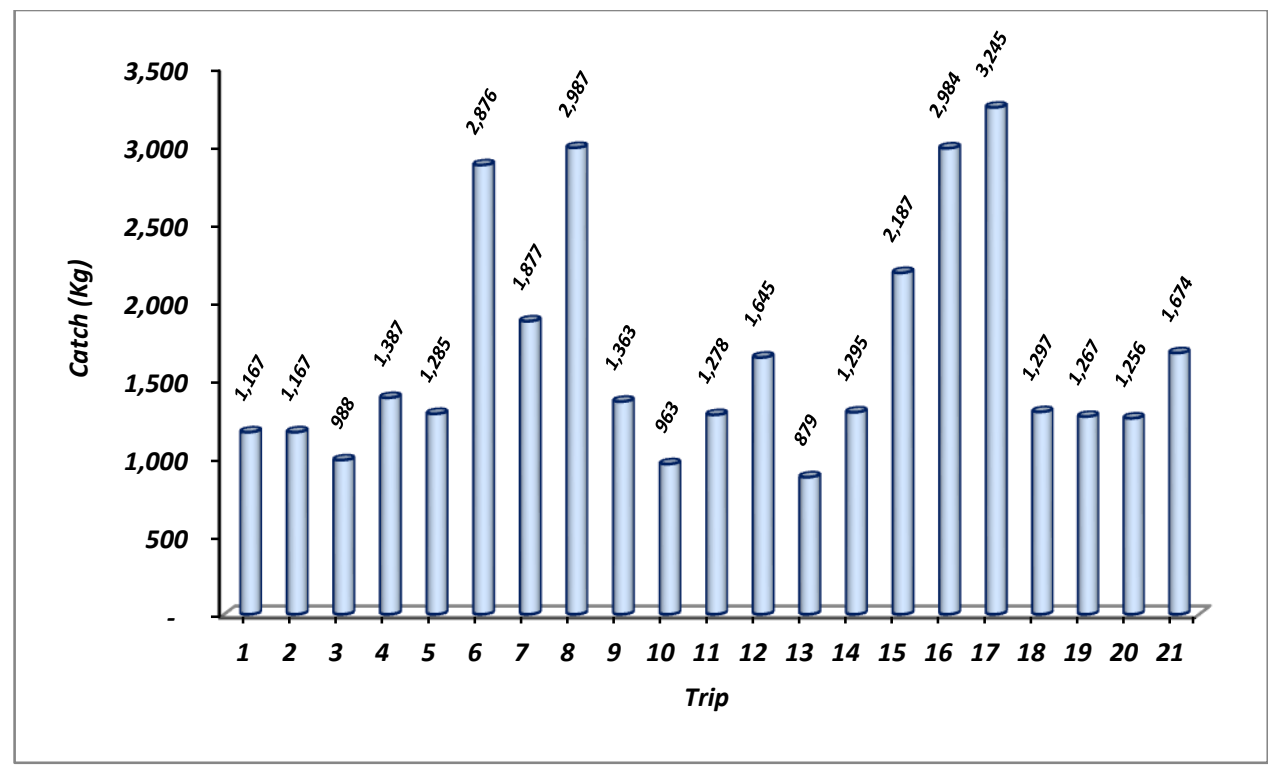

Gambar 1. Hasil Tangkapan Selama Kegiatan Penelitian

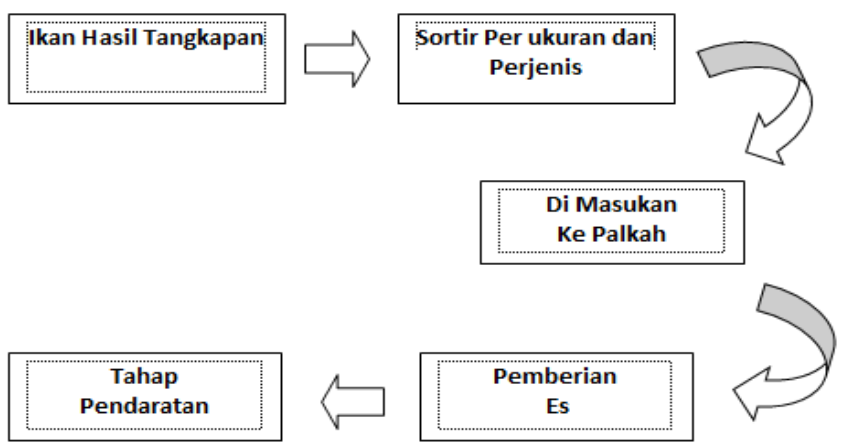

Gambar 2. Proses penanganan ikan pada KM. Inka Mina 523

Penanganan hasil tangkapan merupakan suatu tugas yang harus di selesaikan dengan cepat oleh seluruh anak buah kapal setelah selesai melakukan operasi penangkapan. Penanganan ikan hasil tangkapan dengan baik akan menentukan mutu atau kualitas ikan tersebut sehingga harga ikan pun akan menjadi tinggi. Langkah-langkah yang perlu di ambil dalam melakukan proses penanganan di atas kapal yaitu :

\subsubsection{Sortir}

Setelah selesai operasi penangkapan di adakan pengsortiran. Dalam tahap ini di lakukan pemisahan ikan sesuai dengan ukuran sebelum di masukan ke dalam bak penampung. Tujuan penyortiran yaitu memisahkan menurut kualitas yakni apabila terdapat luka pada tubuh ikan maka dipisahkan dan tidak layak lagi diproses lebih lanjut. Proses penyortiran dilakukan dengan memisahkan hasil tangkapan atau ikan dipisahkan sesuai dengan jenis dan ukuran, ikan yang mengalami luka dipisahkan dan tidak diproses, karena ikan yang mengalami luka akan mempercepat proses kontaminasi bakteri dan dapat merembet hasil tangkapan lainnya.

\subsubsection{Pencucian}

Tahap ini di lakukan untuk membersihkan ikan dari darah serta kotoran yang menempel pada tubuh ikan tujuan tahap ini yaitu untuk mengurangi jumlah bakteri 
yang terdapat pada tubuh ikan sehingga mutu ikan dapat terjaga.

\subsubsection{Penyiapan Es}

Es yang berada pada palka di keluarkan dan di masukan ke dalam karung untuk di hancurkan sampai ukuran yang paling besar berdiameter $5 \mathrm{~cm}$, tetapi rata-rata berdiameter 2 $3 \mathrm{~cm}$, es berfungsi untuk mengurangi pertumbuhan bakteri dan menjaga agar suhu tubuh ikan tetap stabil sehingga pertumbuhan bakteri sangat sedikit sehingga mutu ikan dapat terjaga. Makin kecil ukuran es, makin banyak permukaan ikan yang bersinggungan dengan es, sehingga pendinginan berlansung lebih cepat (Hadiwiyoto, 1993).

\subsubsection{Pendinginan}

Setelah es di siapkan maka pendinginan lansung di mulai dengan cara mencampur ikan dengan es ialah dengan membuat lapisan es pada dasar, kemudian di atasnya di letakkan selapis ikan. Berikutnya, di buat lapisan es dan ikan berganti-ganti, dan di tutup dengan lapisan es sebagai lapisan teratas. Ikan tidak boleh menyinggung dinding wadah, antara ikan dan wadah harus di beri es.

\subsection{Hubungan Parameter Oseanografi dengan} Hasil Tangkapan

Hubungan parameter oseanografi dengan hasil tangkapan kapal pole and line dianlisis dengan menggunakan regresi berganda dengan metode backward, dengan menjadikan hasil tangkapan sebagai variable dependen dan parameter oseanografi sebagai variable independen. Persyaratan yang dipenuhi untuk mendapatkan model regresi terbaik diantaranya uji normalitas dan uji multikolinieritas data. Hasil unit normalitas data menunjukan bahwa hanya variael klorofila saja yang terdistribusi secara normal, sehingga variable hasil tangkapan, SPL dan salinitas di Ln-kan untuk dapat terdistribusi secara normal. Hasil uji normalitas setelah data di Ln-kan terlihat bahwa data tersebut telah terdistribusi secara normal dengan nilai signifikansi kurang dari 0.05 . hasil uji multikolinieritas terlihat bahwa ketida variable independen tidak terjadi multikolinieritas dengan nilai tolerance lebih besar dari 0.1 dan nilai VIF lebih kecil dari 10 (Table 2).

Tabel 2. Hasil Uji Collinieritas

\begin{tabular}{|c|c|c|c|c|c|c|c|}
\hline \multirow{2}{*}{\multicolumn{2}{|c|}{$\begin{array}{c}\text { Model } \\
\text { Dimension } \\
\end{array}$}} & \multirow{2}{*}{ Eigenvalue } & \multirow{2}{*}{$\begin{array}{c}\text { Conditio } \\
n \text { Index }\end{array}$} & \multicolumn{4}{|c|}{ Variance Proportions } \\
\hline & & & & (Constant) & $S P L$ & Klorofil-a & Salinitas \\
\hline \multirow{4}{*}{1} & 1 & 3.836 & 1.000 & .00 & .00 & .01 & .00 \\
\hline & 2 & .164 & 4.842 & .00 & .00 & .54 & .00 \\
\hline & 3 & 5.732E-005 & 258.713 & .00 & .25 & .19 & .29 \\
\hline & 4 & 6.902E-006 & 745.540 & 1.00 & .75 & .27 & .71 \\
\hline \multirow{3}{*}{2} & 1 & 2.853 & 1.000 & .00 & .00 & .01 & \\
\hline & 2 & .147 & 4.399 & .00 & .00 & .55 & \\
\hline & 3 & 1.858E-005 & 391.800 & 1.00 & 1.00 & .44 & \\
\hline
\end{tabular}

Tabel 3. Hasil Uji F

\begin{tabular}{|c|c|c|c|c|c|c|}
\hline & Model & Sum of Squares & $d f$ & Mean Square & $F$ & Sig. \\
\hline \multirow{3}{*}{1} & Regression & 1.931 & 3 & .644 & 9.414 & $.001^{\mathrm{b}}$ \\
\hline & Residual & 1.162 & 17 & .068 & & \\
\hline & Total & 3.093 & 20 & & & \\
\hline \multirow{3}{*}{2} & Regression & 1.910 & 2 & .955 & 14.544 & $.000^{c}$ \\
\hline & Residual & 1.182 & 18 & .066 & & \\
\hline & Total & 3.093 & 20 & & & \\
\hline
\end{tabular}

a. Dependent Variable: Catch

b. Predictors: (Constant), Salinitas, Klorofil-a, Suhu Permukaan Laut

c. Predictors: (Constant), Klorofil-a, Suhu Permukaan Laut

Hasil Uji F untuk melihat pengaruh parameter oseanografi secara bersama-sama terhadap hasil tangkapan (Tabel 3) menunjukan secara bersama-sama parameter oseanografi berpengaruh nyata terhadap hasil tangkapan pada model pertam, setelah dianalisis kembali dengan menggunakan model kedua terlihat bahwa hanya nilai SPL 
dan klorofil-a yang berpengaruh nyata terhadap hasil tangkapan, hal ini ditunjukan dengan nilai nilai signifikansi yang diperoleh 0.000 kurang $\alpha(0.05)$ dengan $F_{h i t} 14.544>F_{t a b(0.05)}$ =3.172). nilai koefisien korelasi dari persamaan regresi adalah $(R)=0.786$ dengan $\left(R^{2}\right)=0.618$ atau dapat dikatakan bahwa $61.8 \%$ hasil tangkapan di pengaruhi oleh factor klorofil-a dan SPL sisanya $39.1 \%$ dipengaruhi oleh factor lainnya.
Model regresi yang terbentuk dan digunakan untuk menjelaskan hubungan parameter oseanografi dengan hasil tangkapan di pesisir pulau Batang Dua adalah $Y=24.025$ $5.048 X_{1}+2.516 X_{2}$, dengan $X_{1}$ adalah suhu permukaan laut dan $X_{2}$ adalah klorofil-a. Gambar 6 menunjukan grafik Hubungan antara hasil tangkapan lapangan dan hasil tangkapan prediksi.

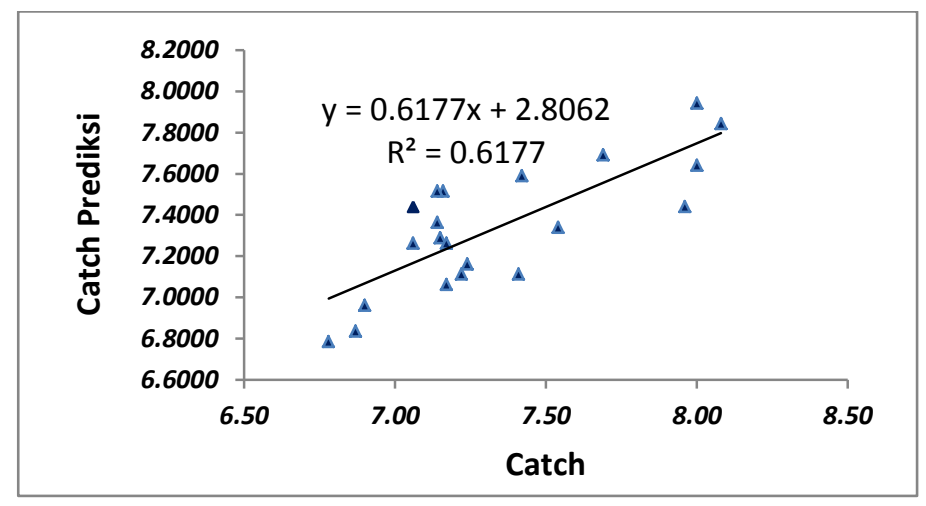

Gambar 3. Grafik Hubungan antara Hasil Tangkapan Lapangan dengan Tangkapan Prediksi

Hasil Uji $t$ dipakai untuk melihat pengaruh faktor oseanografi terhadap hasil tangkapan secara individual menunjukan bahwa pada model 2 variable salinitas dikeluarkan dari model hal ini diakibatkan karena nilai salinitas secara individu tidak berpengaruh nyata terhadap hasil tangkapan. Kecilnya nilai korelasi antara hasil tangkapan dan salinitas $(r=0.056)$ diduga karena hasil tangkapan (ikan cakalang, madidihang dan tongkol) merupakan jenis ikan pelagis yang hidup di dekat permukaan yang cenderung homogen sehingga fluktuasi salinitas pada daerah ini sangat kecil. Selain itu pada perairan tropis umumnya fluktuasi salinitas sangat kecil dan salinitas juga tidak tampak sebagai faktor yang mempengaruhi distribusi ikan tuna tetapi mencirikan massa air yang dapat membantu mengenal daerah penangkapan yang lebih potensial (Stequert dan Marsac (1989) dalam Waas (2004)).

Nilai signifikansi suhu permukaan laut dan klorofil (Tabel 4) pada model 2 lebih kecil dari $\alpha(0.05)$ dengan nilai suhu permukaan laut 0.028 dan klorofil-a $\mathbf{0 . 0 1 8}$, nilai ini menunjukan bahwa secara individual parameter oseanografi berpengaruh nyata terhadap hasil tangkapan ikan.

Tabel 4. Hasil Uji t Hasil Tangkapan dengan Suhu Permukaan Laut dan klorofil-a

\begin{tabular}{|c|c|c|c|c|c|c|}
\hline & \multirow[t]{2}{*}{ Model } & \multicolumn{2}{|c|}{$\begin{array}{c}\text { Unstandardized } \\
\text { Coefficients }\end{array}$} & \multirow{2}{*}{$\begin{array}{c}\begin{array}{c}\text { Standardized } \\
\text { Coefficients }\end{array} \\
\text { Beta }\end{array}$} & \multirow[t]{2}{*}{$t$} & \multirow[t]{2}{*}{ Sig. } \\
\hline & & $B$ & Std. Error & & & \\
\hline \multirow{3}{*}{2} & (Constant) & 24.025 & 9.221 & & 2.606 & .018 \\
\hline & Suhu Permukaan Laut & -5.048 & 2.701 & -.361 & -1.869 & .028 \\
\hline & Klorofil-a & 2.516 & .969 & .501 & 2.597 & .018 \\
\hline
\end{tabular}

Hasil analisis regresi polinomial untuk melihat hubungan dari suhu permukaan laut dan klorofil-a secara individual terhadap hasil tangkapan dapat dilihat pada Gambar 7 dan
Gambar 8. Gambar 7 dapat dilihat bahwa hasil tangkapan ikan cakalang, ikan madidihang dan ikan tongkol yang ditangkap dengan menggunakan kapal pole and line umumnya 
tertangkap pada kisaran SPL $28-31^{\circ} \mathrm{C}$ dengan hasil tangkapan tertinggi terdapat suhu 28.5 29. $5{ }^{\circ} \mathrm{C}$, Koefisien determinasi $\left(R^{2}\right)$ antara SPL dan hasil tangkapan adalah 0.4228 artinya pengaruh yang diberikan dari SPL terhadap hasil tangkapan sebesar $42.28 \%$ dan sisanya dipengaruhi oleh factor lain. Hubungan yang signifikan antara SPL dan hasil tangkapan diduga disebabkan karena ikan cakalang, madidihang dan tongkol pada umumnya merupakan predator yang selalu berada di lapisan permukaan pada siang hari untuk berburu mangsanya (Gradieff, 2003). Menurut Leavsetu dan Hela (1970), tuna dan little tuna merupakan jenis ikan pelagis yang dalam kelompok ruayanya akan muncul dipermukaan laut pada siang hari dan akan beruaya ke dalam permukaan pada sore hari. Hal yang didapat dari Gambar 4 adalah hasil tangkapan akan menurun seiring dengan naiknya suhu permukaan laut.

Gambar 5 menunjukan bahwa hubungan nilai klorofil-a dengan hasil tangkapan ikan cakalang, madidihang dan tongkol, dimana hasil tangkapan umumnya tertangkap pada kisaran konsentrasi klorofil-a $0.03-0.35 \mathrm{mg} / \mathrm{m}^{3}$, dengan nilai koefisien determinasi dapat dilihat bahwa hubangan antara klorofil-a dengan hasil tangkapan adalah sebesar 0.5313 artinya $53.13 \%$ hasil tangkapan dipengaruhi oleh klorofil-a sisanya dipengaruhi oleh factor lain. Besarnya nilai hubungan kllorofil-a dengan hasil tangkapan tersebut diduga karena Pengaruh yang nyata antara konsentrasi klorofil-a dengan hasil tangkapan ikan yellowfin tuna, diduga karena nilai rerata konsentrasi klorofil-a pada lapisan permukaan perairan laut Halmahera cukup tinggi hingga mendekati $0.4 \mathrm{mg} / \mathrm{m}^{3}$. Menurut Loukos et al. (2003), bahwa fitoplankton bukan merupakan makanan alami tuna tetapi sebagai rantai dasar makanan tuna. Produksi tersier dan sekunder membuat makanan tuna (forage) bergantung pada produktivitas primer fitoplankton. Menurut Nontji (2002), bahwa perairan yang produktivitas primer planktonnya tinggi akan mempunyai sumberdaya hayati perairan yang besar pula. Hal yang dapat dilihat adalah kenaikan nilai konsentrasi klorofil-a juga berpengaruh terhadap kenaikan hasil tangkapan.

3.3. Sebaran Parameter Osenografi dengan Hasil Tangkapan

Hasil analisis statistic menunjukan bahwa dari tiga parameter oseanografi yang diteliti terdapat dua parameter yang berpengaruh nyata secara individual terhadap hasil tangkapan ikan dengan pelagis besar (Ikan cakalang, madidihang dan tongkol) dengan menggunakan alat tangkap pole and line yakni suhu permukaan laut dan klorofil-a.

\subsubsection{Suhu Permukaan Laut (SPL)}

Suhu adalah faktor lingkungan yang paling mudah untuk diteliti dan ditentukan. Fluktuasi air laut banyak dipengaruhi oleh iklim, suhu udara, kekuatan arus, kecepatan angin, lintang maupun keadaan relif dasar laut. Fluktuasi harian suhu permukaan, misalnya, pada umumnya tidak akan lebih dari $0.2-0.4{ }^{\circ} \mathrm{C}$, sedangkan didekat pantai fluktuasi tersebut bisa mencapai beberapa derajat celsius besarnya.

Sebaran suhu permukan laut (SPL) selama musim peralihan I (Maret - Mei 2015) dapat dilihat pada Gambar 6. Gambar 6 menunjukan bahwa pada musim peralihan I kisaran SPL pada perairan terbuka berada dibawah $29^{\circ} \mathrm{C}$ dan kisaran suhu tertinggi lebih besar dari $29^{\circ} \mathrm{C}$ umumnya berada dipesisir pulau Halmahera. SPL pada daerah penangkapan selama penelitian sangat berfluktuasi pada kisaran $28.3-30.8{ }^{\circ} \mathrm{C}$, dengan rata-rata SPL selama penangkapan adalah 29.34 ${ }^{\circ} \mathrm{C}$. fluktuasi SPL yang terjadi juga berpengaruh terhadap pengkonsentrasian gerombolan ikan. Menurut Gunarso, 1985, fluktuasi suhu dan perubahan geografis merupakan faktor penting dalam upaya merangsang dan menentukan pengkonsentrasian gerombolan ikan. Selanjutnya fluktuasi suhu permukaan laut diduga dipengaruhi oleh kondisi meteorologi. Laevestu dan Hela (1970) menyatakan bahwa faktor-faktor yang mempengaruhi suhu permukaan air laut (SPL) adalah kondisi meteorologi, arus permukaan, ombak, upwelling, divergensi, konvergensi dan perubahan bentuk es di daerah kutub. 




Gambar 4. Hasil Analisis Regresi Polinomial SPL dengan Catch

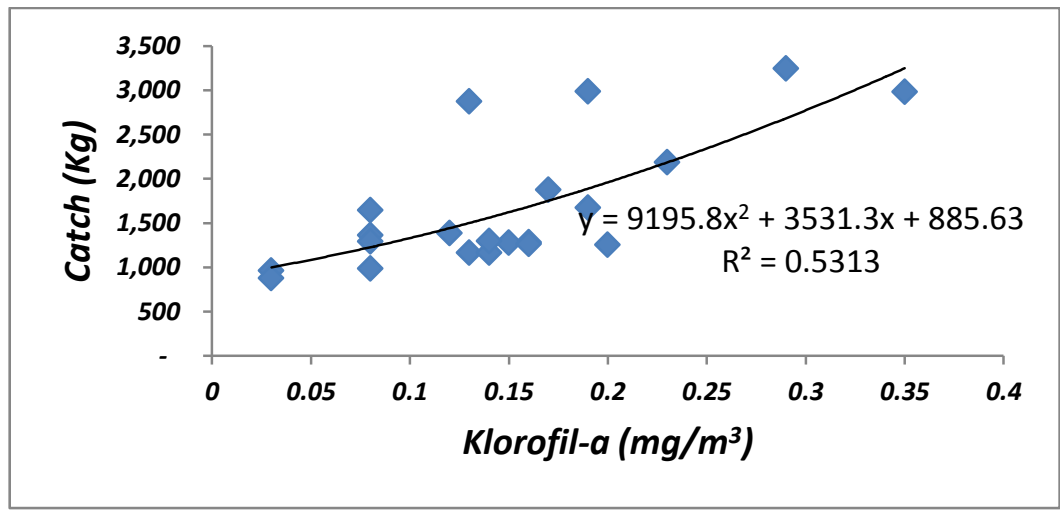

Gambar 5. Hasil Analisis Regresi Polinomial Klorofil-a dengan Catch

\subsubsection{Klorofil-a}

Konsentrasi klorofil-a biasa disebut dengan figmen photosintetik dari phytoplankton. Pigmen ini dianggap sebagai indeks terhadap tingkat produktivitas biologis. Di perairan laut, indeks klorofil ini dapat dihubungkan dengan produksi ikan atau menggambarkan tingkat produktivitas daerah penangkapan ikan karena digunakan sebagai ukuran banyaknya fitoplankton pada suatu perairan tertentu.

Konsentrasi klorofil-a selama penelitian (Maret-Mei 2015) dapat dilihat pada Gambar 7. Gambar 7 menunjukan bahwa sebaran konsentrasi klorofil-a pada musim peralihan I (Maret-Mei 2015) berada pada kisaran 0.15 - 0.35 $\mathrm{mg} / \mathrm{m}^{3}$ denga kisaran konsentrasi klorofil-a tertinggi terdapat di pesisir pulau Halmahera. Kisaran konsentrasi klorofil-a pada daerah penangkapan berkisar antara $0.03-0.35 \mathrm{mg} / \mathrm{m}^{3}$ dengan nilai rata-rata $0.2 \mathrm{mg} / \mathrm{m}^{3}$. Menurut Gower (1972) bahwa keberadaan konsentrasi klorofil-a diatas $0.2 \mathrm{mg} / \mathrm{m}^{3}$ mengindikasikan keberadaan plankton yang cukup untuk menjaga kelangsungan hidup ikan-ikan ekonomis penting. Terdapat hubungan yang nyata antara konsentrasi klorofil-a dengan hasil tangkapan diduga karena distribusi hasil tangkapan (tuna) lebih mendekati area dengan produktivitas yang tinggi dan atau front antara massa air yang diketahui sebagai agregat konsentrasi makanan tuna (Yamamoto dan Nishizawa, 1986 dalam Waas, 2004). Cayre et al (1993) dalam Watimury (1998), menyatakan bahwa pergerakan tuna dan cakalang menuju zone yang relatif kaya kandungan klorofil-a merupakan hal yang sangat vital dan agregasinya ditemukan pada area konsentrasi makanan. 

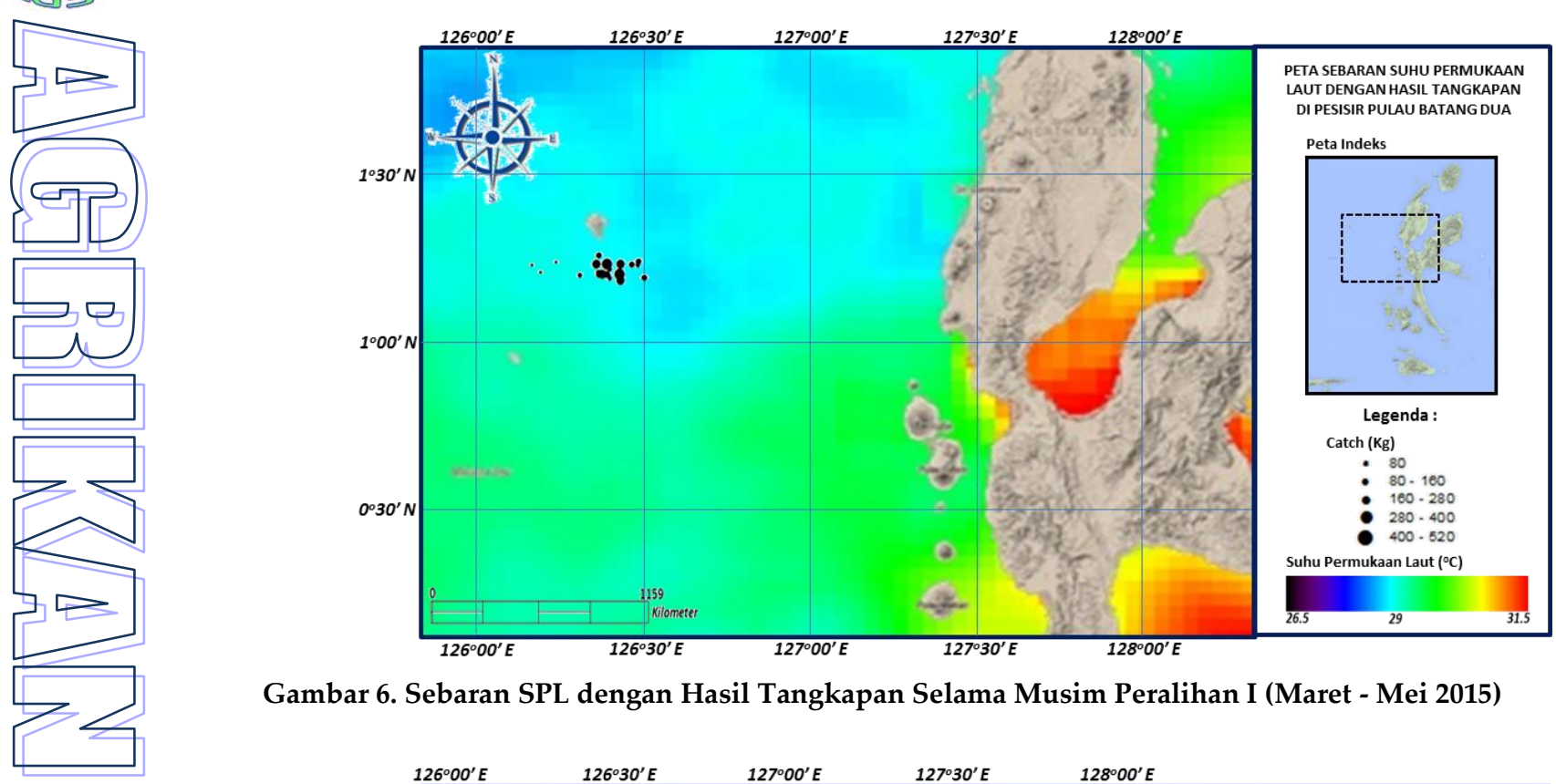

Gambar 6. Sebaran SPL dengan Hasil Tangkapan Selama Musim Peralihan I (Maret - Mei 2015)

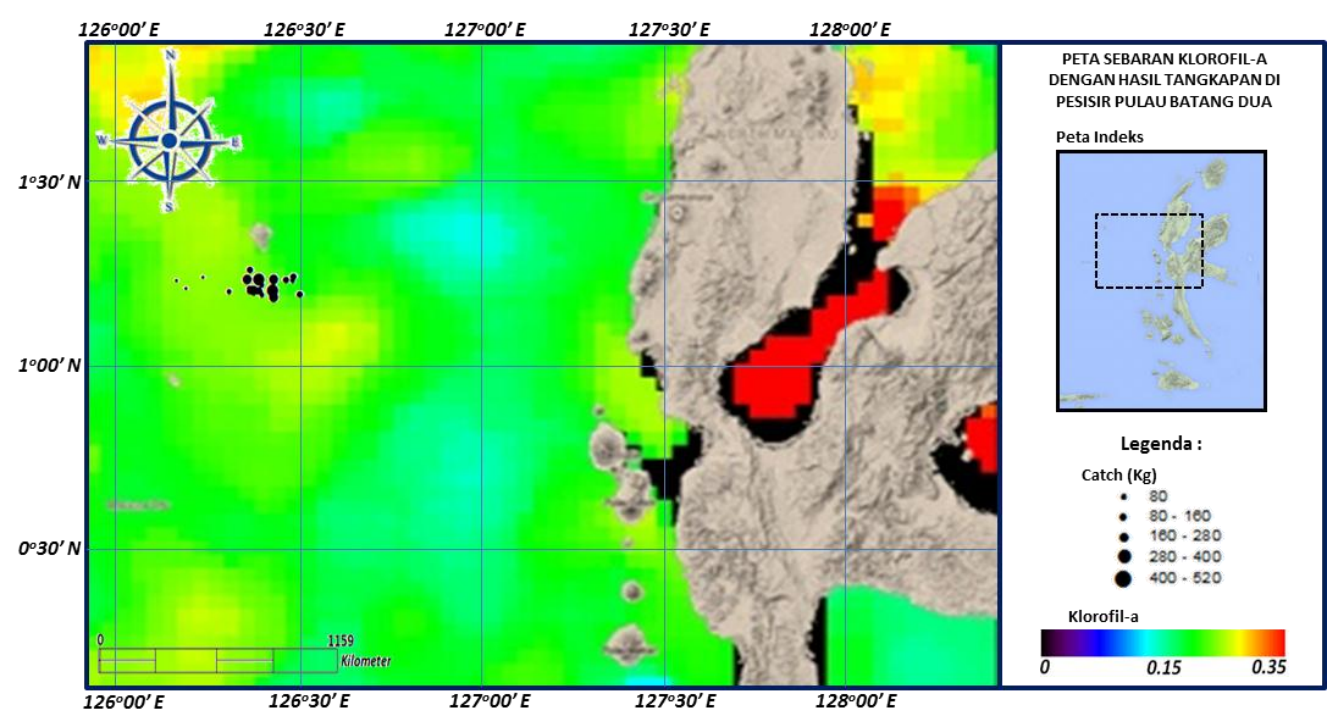

Gambar 7. Sebaran Klorofil-a dengan Hasil Tangkapan Selama Musim Peralihan I (Maret-Mei 2015)

\section{PENUTUP}

\subsection{Kesimpulan}

Hasil penelitian menunjukan bahwa :

1. Hasil Uji F menunjukan bahwa parameter oseanografi diantaranya suhu permukaan laut dan salinitas secara bersama-sama berpengaruh terhadap hasil tangkapan (ikan cakalang, madidihang dan tongkol) dengan $\left(F_{\text {Hit }} 14.544>F_{\text {Tabel }}\right.$ 3.172) dan $R^{2}=$ 0.618 .

2. Hasil uji $t$ didapatkan bahwa secara individu hasil tangkapan hanya dipengaruhi oleh dua factor oseanografi yakni SPL dan Klorofil-a dengan nilai koefisien determinasi $\left(R^{2}\right)$
0.4228 untuk SPL dan 0.5313 untuk Klorofil-a.

3. Sebaran SPL pada daerah penangkapan selama penelitian (Maret-Mei 2015) adalah 28.3-30.8 ${ }^{\circ} \mathrm{C}$ dengan rata-rata SPL selama penangkapan adalah $29.34{ }^{\circ} \mathrm{C}$ dan total jumlah hasil tangkapan $1.669 .93 \mathrm{~kg}$

4. Sebaran klorofil-a pada daerah penangkapan selama penelitian (MaretMei 2015) adalah $0.03-0.35 \mathrm{mg} / \mathrm{m}^{3}$ dengan rata-rata konsentrasi klorofil-a 0.2 $\mathrm{mg} / \mathrm{m}^{3}$ selama penangkapan.

\section{2. $\mathrm{S}$ a r a $\mathrm{n}$}

Mengingat data penelitian yang didapat masih tergolong sedang sehingga penulis 
menyarankan untuk perlu dilakukan penelitian lanjut untuk mendapatkan data yang lebih banyak terhadap parameter ketiga parameter oseanografi tersebut dan parameter oseanografi lainnya setiap musim sehingga validitas hasil penelitian dapat digunakan oleh nelayan dalam mengeksploitasi sumberdaya perikanan di Laut Maluku khususnya perairan Batang Dua.

\section{DAFTAR PUSTAKA}

Baskoro, M. S dan Effendy, A., 2005. Tingkah Laku Ikan : Hubungannya dengan Metode Pengoperasian Alat Tangkap Ikan. Departemen Pemanfaatan Suberdaya Perikanan. IPB. Bogor.

FAO, 1983. FAO Species Catalogue Vol. 2 Scombrids of The World An Annotated And llustratted Cataloque of Tunas, Mackerel, Bonitas and Related Species Known to Date. Rome. UN.

Gunarso. W., 1985. Tingkah Laku Ikan dalam Hubungannya dengan Alat, Metode dan Taktik Penangkapan. Diktat Kuliah (Tidak di Publikasikan). Jurusan Pemanfaatan Sumberdaya Perikanan. Fakultas Perikanan. Institut Pertanian Bogor. Bogor. 149 hal.

Hendiarti N., 2008. Hubungan Antara Keberadaan Ikan Pelagis Dengan Fenomena Oseanografi Dan Perubahan Iklim Musiman Berdasarkan Analisis Data Penginderaan Jauh. Globe Vol 10, 19 , dan 25.

Itano, G., 2005. A Handbook for the Identification of Yellowfin and Bigeye Tunas in Fresh Condition. 1st Meeting of the Scientific Committee of the Western and Central Pacific Fisheries Commission WCPFC-SC1 Noumea, New Caledonia.

Laevastu T, dan I. Hela., 1970. Fisheries Oceanography. London: Fishing News $238 \mathrm{hlm}$.

Nurdin S., 2009. Penentuan Zona Penangkapan Potensial dan Pola Migrasi Ikan Kembung (Restrelliger spp) di Perairan Kecamatan Liukang Tupabbiring Kabupaten Pangkep. Thesis S2 Univeristas Hasanuddin Makassar.

Saanin, H. 1984. Taksonomi dan kunci Identifikasi Ikan. Jilid I dan II. Bina Cipta, Bogor.

Sadhori, N. 1985. Teknik Penangkapan Ikan. Angkasa. Bandung.

Sediadi A. dan Edward., 2000. Kandungan Klorofil-a fitoplankton diperairan Pufau-Pulau Lease Maluku Tengah. PUSLILTBANG OSEANOLOGI-LIPL.

Supadiningsih, C. N. dan Rosana, N., 2004. Penentuan Fishing Ground Tuna dan Cakalang Dengan Teknologi Penginderaan Jauh. Disampaikan pada Pertemuan Ilmiah Tahunan I Teknik Geodasi. ITS-Surabaya.

Santosa, S. et al. 2005. Menggunakan SPSS untuk Statistik Parametrik. Seri Solusi Bisnis berbasis Tl. PT. Elex Media Komputindo. Kelompok Gramedia. Jakarta.

Tajudin, M. 2010. Pengkajian Daerah Potensi Ikan Madidihang(Thunnus albacares). Staff Dosen UNHALU Kendari Prov. Sulaswesi Tenggara. [http://tadjuddahmuslim.wordpress. com/2009/01/28/ pengkajian-daerah-potensi-ikan-madidihang-thunnus-albacares. (di download tanggal 23 Septembr 2015)]

Waas, H. J. 2004. Analisis Daerah Potensial Penangkapan Cakalang (Katsuwonus pelamis) dan Madidihang (Thunnus albacares) di Perairan Utara Papua, Pasifik Barat. (Thesis) [tidak dipublikasikan]. Bogor. Teknologi Kelautan Institut Pertanian Bogor. 